\title{
GEOINFORMATIONAL \\ SUPPORTING OF GEOTECHNOLOGIES
}

\author{
Viktor Alenichev ${ }^{1 *}$ \\ ${ }^{1}$ Institute of Mining, Ural Branch of the Russian Academy of Sciences, Ekaterinburg, Russia
}

\begin{abstract}
The use of complex geotechnical systems, helping for a comprehensive exploitation of mineral resources, is possible only in combination of physical and technical methods of the physical, chemical, biohydro-metallurgical and other special geological technologies of extraction of useful components from natural deposits and man-made formations. To substantiate the parameters of geotechnologies and of extraction indicators of the useful component, information is needed about the modes of processes in the rock mass characterized by certain properties. The creation of a geodatabase, including the characteristics of the material composition and technological properties of the mineral in various fields, will allow to form a database of technological knowledge for the selection of the method of extraction of minerals from the depths and enrichment schemes based on the classification of situations. The bank of technological knowledge should be formed as a multi-level structure that takes in account the physical phenomena and effects accompanying the extraction of a useful component from the depths, technological methods of mining, geotechnological methods and processes of raw material extraction, its processing and enrichment, modes of technological processes. Key words: geoinformation supporting, complex field, geotechnology, extraction, geodata, formation, knowledge bank.
\end{abstract}

\section{Introduction}

Technologies of development of solid mineral deposits are based on the use of processes: physical-and-technical, physical, physical-and-chemical, chemical, biohydrometallurgical and other or their combinations. To choose an effective method of extracting a useful component directly from the subsoil, information is needed about the impact of the mining environment on the regime of a specific technological process. The traditional mining process, based on the physical-and-mechanical properties of the mineral, is associated with the extracting from the entrails of the earth some crushed or friable rock mass and its subsequent transportation to the points of further processing, storage and stockpilling. This technology, preserving the qualitative characteristics, physical and chemical properties, texture-and-structure features of the mineral in the extracted raw materials, is associated

\footnotetext{
"Corresponding author: alenichev@,igduran.ru
} 
with high costs for the transfer of rock mass to the mobile state, transportation of waste rock into dumps and ores to the points of bringing it to the state, a satisfying a customer.

\section{Research of the question}

The way out of this situation is the use of mining-technical systems focused on the full cycle of geotechnological processes of extraction and processing of raw materials and providing an increase in the field geopotential [1, 2]. The conversion to complex geotechnical systems in the present time can be carried out only when combination of physical-and-technical methods with physical, chemical, biohydrometallurgical and other special geotechnologies of extraction of useful components from natural deposits and manmade formations. The possibility of using optimal technologies and complex geotechnical systems is determined by the results of a system analysis of geological, mining, hydrogeological, geochemical conditions, texture-and-structure characteristics and the material composition of the mineral $[3,4]$. At the same time, it is necessary to revise The State Balance taking into account the development of various industry and energy branches, modern market requirements, international standards for estimating of mineral resources and reserves [5]. The "Guidelines for the preparation of feasibility studies of conditions" should identify the features of research on the phases and stages of exploration, taking into account the type of mineral raw material and the complexity of the field [6].

Minerals are mainly presented in the form of compounds that have arisen as a result of certain geological processes: magmatism, metamorphism, destruction and sedimentation. Minerals located in the Earth's entrails are characterized by certain physical properties, chemical composition and internal structure [4]. The number of stable natural compounds minerals - does not exceed three thousand. By chemical composition the minerals are divided into simple substances: sulfides, halides and oxygen compounds. Most minerals have a crystalline structure and only some of them are amorphous. The physical properties of minerals are very diverse and are predetermined by the chemical composition and internal structure. The choice of geotechnological method of extraction depends on the texture-and-structure features of the mineral and the enclosing rocks, which are associated with the size, shape and relative position of grains, aggregates and inclusions [7, 8].

The basis of a particular geotechnological method is physical, chemical, biochemical, electrochemical, thermal, photo, electromagnetic, radioactive and other processes, and often their combinations. Therefore, to assess the parameters of geotechnologies and of extraction indicators of the useful component, we need information about the flow regimes of a particular process in the rock mass characterized by a complex of properties. The classification of physical properties of rocks is based on their reaction to external fields or influences, in interaction with which specific properties are shown. In accordance with this postulate, the following classes of properties are distinguished: density, mechanical, thermal, electromagnetic, radiological, mining-technological and others.

When using geotechnologies of selective extraction, detailed information about the physical properties, chemical and mineralogical composition of the mineral, the processes of its transfer to the mobile state, morphology, texture-and-structure features of ores, the minimal industrial matter of mineral components in the block, the technological effectiveness of the mineral and the onboard content. On the basis of technological studies of the productive strata and of the host rocks, additional indicators are being established which characterize a certain geotechnology and are necessary for effective impact on the mountain massif and for extraction of the useful component from the depths. 
The most popular physical and technical techniques of the mining industry are mainly associated with the development of solid mineral deposits by open, underground and combined methods. Physical and physic-chemical geotechnological methods of extracting the useful component from the subsoil are: heap and underground leaching, underground dissolution, underground smelting, underground gasification, borehole hydro production. These methods allow extracting the useful component directly from the subsoil, excluding traditional methods of mining operations. Heap and underground leaching are used while the extraction of precious, non-ferrous, rare and radioactive metals, underground dissolution - by the operation of salt deposits and by the creation of underground tanks. Underground smelting is widely used by the extraction of sulfur. Underground gasification, based on the transfer of minerals into gaseous state, is used by the extraction of coal, shale, peat, heavy oil and bitumen. Boreholes hydraulic mining, classified as a processing technology, used in the extraction of useful component (components) from the productive mass by its hydro-mechanical destruction. The implementation of geotechnologies for selective extraction of only useful components from the subsoil requires the study of physical, physical-and-chemical and many other processes, as well as the search for new qualitative innovations in mining practice. Along with the generally accepted characteristics of the field the creation of geoinformation support of physical and chemical geotechnologies should use the concept of "physical and geological environment", including geological, hydrogeological and geothermal characteristics of the deposit, physical and chemical properties of minerals and host rocks. A detailed study of the "physical-geological situation" gives a perspective view for the ability of the mineral to move into a mobile state by means of erosion, dissolution, leaching, combustion, melting, sublimation, etc. The development of geodatabases describing the characteristics of the physical composition and technological properties of minerals in various fields will allow forming in the future a database of technological knowledge for selecting the method of extraction of minerals from the depths and enrichment schemes based on the classification of situations. The realization of this measure will lead to a reduction of the search area, to reasonable consideration of the characteristics of the object of research, to making conclusions about the expected results and improving the quality of design decisions $[9,10]$.

Herewith, situations can be structured according to various technical and technological features: physical and mechanical properties of rocks and minerals, content of useful and harmful components, grades and types of ores, natural varieties, characteristics of the distribution of minerals by size, morphology, etc. As a criterion of structuring contrast technological properties, a rational complex of methods and apparatus of ore preparation and enrichment cycles can be used. The classified situations, together with non-standard situations, stored in the form of statistically accumulated data, will allow to expand the knowledge base used to select the mode of extraction, processing of poor and difficult-to-rich raw materials and man-made waste, which will provide further justification for the promising internal structure of the projected geotechnology of mining of mineral resources and technologies for its processing.

The bank of technological knowledge should be formed as a multi-level structure that accumulates knowledge in the following areas: physical phenomena and effects, reflecting the technology of extracting a useful component from the depths; technological method (methods) of mining, geotechnological methods and processes of extraction of raw materials, its processing and enrichment, modes of technological processes in the extraction of a useful component of their subsoil. The procedure for the creation of such knowledge bank requires the solution of complex problems, the main ones are: the rationale for a 
universal conceptual framework for describing the subject area of the investigation of extraction of useful component from the subsoil, the improvement of modules of knowledge representation, the creation of effective methods and means of forming knowledge bases, and creation of information support and special software. In essence, the bank should be a computer system designed to classify, accumulate, store and issue knowledge at the request of the user, control the truth of the postulates (regularities) used. The difference between the bank of technological knowledge and presently known systems of storage and issuance of technological data is that it is possible to extract new, previously unknown for specific conditions technological solutions that are not stored in a suitable form for instant use, but can be synthesized as a result of the interaction of the in the bank existing knowledge. When creating geoinformation support for complex fields and deposits, objective geodata about texture-and-structure characteristics and morphological features of the mineral, as well asabout the chemical composition and physical properties of the rock mass are needed $[11,12]$.

\section{Summary}

1. Foundation of physical-and-technical geotechnologies constitute explosive, mechanical, hydraulic, cryogenic, chemical, gravitational and other effects on the rock mass, due to which destruction of rocks, strengthening and stabilization of mine workings and massifs, transportation of minerals to the enrichment points and of waste rocks to the dump are carried out.

2. For the successful implementation of physical, physical-chemical and other new geotechnologies designed for extracting the useful component directly from the subsoil, it is necessary to accelerate researching activities on the creation of the geoinformation support system and of the knowledge bank, based on the optimal modes of the relevant processes.

\section{References}

1. Kaplunov D.R., Ruban A.D., Rylnikova M.V. Integrated development of mineral resources united by geotechnologies. NIIK Nedra XX1 LLC. 304 p. (2010)

2. K. N.Trubetskoy, G.L. Krasnyansky, V.V. Khronin, V.S. Kovalenko. Designing of opencast mines. 3rd ed. Higher education. 694 p. (2009)

3. Doroshenko M.V., Bashlykova T.V. Technological properties of minerals. Heat-andpower engineer. 296 p. (2007).

4. Bashlykova T.V. Rational development of mineral resources. 5 - 6. 4 - 14. (2015)

5. Ilin O.V. Subsoil use of the XX1 century. 2 (71). 112 - 115. (2018)

6. Ivanov S.M., Annenkova T.E., Casanov O.V., Kushnarev P.I. Subsoil use of the XX1 century. 2 (71). 106-110. (2018)

7. Trubetskoy K.N. Mine surveying and subsoil use. 3. 22 - 29. (2010)

8. Borisov F.F., Alenichev V.M. Mining Information Analytical Bulletin. 10. 256 - 262. (2015)

9. Sukhanov V.I., Alenichev V.M. Mining information-analytical bulletin. 11. 320-329. (2015)

10. Alenichev V.M., Alenichev M.V. Problems of subsoil use. 1 (8): peer reviewed. sci. articles. Ekaterinburg: IGD UB RAS. 12 - 19. (2016)//trud.igduran.ru.

11. Alenichev V.M., Sukhanov V.I. Mining Inform. and Analyt. Bulletin. 8. 5 - 15. (2016)

12. Larionov A.N., Kalinichenko L.S., Ryazanov M.A. Rational development of subsoil. 5 6. 51 - 52. (2015) 